\title{
Neonatal lupus syndrome: a case with chondrodysplasia punctata and other unusual manifestations
}

\author{
E Austin-Ward, S Castillo, M Cuchacovich, A Espinoza, J Cofré-Beca, S González, \\ $\mathrm{X}$ Solivelles, J Bloomfield
}

\begin{abstract}
We report a case of a newborn infant whose mother had systemic lupus erythematosus (SLE) diagnosed before pregnancy. The child had clinical manifestations of neonatal lupus as well as chondrodysplasia punctata and other findings that resemble the congenital anomalies associated with the use of oral anticoagulants, with no history of exposure. We speculate that the combined action of the different maternal autoantibodies may produce the whole spectrum of manifestations.

(F Med Genet 1998;35:695-697)
\end{abstract}

Keywords: neonatal lupus erythematosus; chondrodysplasia punctata; anti-Ro/SSA antibodies; antiphospholipid antibodies

Neonatal lupus erythematosus (NLE), characterised by congenital atrioventricular heart block or transient lupus skin lesions or both, ${ }^{1}$ is considered to be caused by passively acquired autoimmunity via the placenta. ${ }^{2}$ In addition, the use of oral anticoagulants between 6 and 9 weeks of gestation can cause congenital abnormalities, consisting of intrauterine growth retardation (IUGR), hypotonia, craniofacial abnormalities with a hypoplastic nose, chondrodysplasia punctata (stippled epiphyses), hypoplastic nails, and other manifestations. ${ }^{34}$ In this report we present a patient with neonatal lupus with uncommon manifestations ressembling both syndromes.

\section{Case report}

The proband was born to unrelated, young, Chilean parents. The 19 year old primigravida had systemic lupus erythematosus diagnosed at the age of 16, when she presented with symmetrical polyarthritis, malar rash, cervical lymphadenopathy, and pleural effusion. The haemoglobin level was $15 \mathrm{~g} / \mathrm{dl}$. The white cell count was 5400 with normal differentiation and platelet count. ESR was $90 \mathrm{~mm} / \mathrm{h}$. She had (+) ANA 1/6400 titre in a speckled pattern, $(+)$ anticardiolipin antibodies IgG (53.2 GPL), (+) ENA, (+) RNP, (+) Ro, (-) anti-ds DNA, (-) lupic anticoagulant. $\mathrm{C} 3, \mathrm{C} 4, \mathrm{BUN}$, creatinine, and urine samples were in the normal range. She showed a positive clinical response to treatment with hydroxychloroquine $200 \mathrm{mg} /$ day, ketoprofen, and aspirin $100 \mathrm{mg} /$ day. However, six months later (during this treatment) she developed flare with fatigue, malaise, weakness, weight loss, anaemia, hypocomplementaemia, severe polyarthritis, and a large pericardial effusion with evidence of right ventricular volume and pressure overload. Because of these symptoms, prednisone at a dosage of $30 \mathrm{mg} /$ day and azathioprine at a dosage of 200 $\mathrm{mg} /$ day were prescribed. The symptoms remitted and azathioprine was discontinued when she was 17 years old. Nine months later she became pregnant. During the first month of pregnancy, she was taking hydroxichloroquine $200 \mathrm{mg} /$ day, aspirin $100 \mathrm{mg} /$ day, and prednisone $10 \mathrm{mg} /$ day. When her pregnancy was diagnosed at four weeks postconception, hydroxichloroquine was discontinued. She continued with prednisone and aspirin. There was no history of exposure to warfarin or derivatives before or during pregnancy.

Laboratory tests showed anaemia, leucopenia, (+) ANA, (+) anti-ds DNA, hypocomplementaemia, (+) anticardiolipin antibodies, IgG, and (-) lupic anticoagulant. She discontinued all medication after the third month of pregnancy. At 33 weeks a female was born by caesarean section because of acute fetal distress and IUGR. Apgar scores were 8 and 9 at one and five minutes respectively, birth weight was $1500 \mathrm{~g}$, and length $39.5 \mathrm{~cm}$. The placenta showed multiple infarctions. Two weeks after delivery, the mother had a severe lupic crisis with (+) anti-Ro antibodies, (+) ANA, severe hypocomplementaemia, high levels of anticardiolipin IgG antibodies, and positive lupic anticoagulant, which was negative at the beginning of the pregnancy. Protein $C$ and $S$ were in the normal range.

CLINICAL MANIFESTATIONS

The child had facial dysmorphism consisting of poorly developed brow ridges, depressed nasal bridge and nasal hypoplasia, large philtrum, thin pinnae, and a prominent occiput. Skin lesions consisted of small, $0.5 \mathrm{~cm}$ annular plaques limited to the face, around the lateral sides of the orbits in an almost symmetrical distribution. The lesions were erythematoviolaceous, scaling, and depressed (fig 1). Histology of a skin lesion showed orthokeratosis, normal thickness for age, and slightly spongy epidermis. There was superficial and perifollicular lymphocytic and histiocytic infiltration, epidermal focal vacuolar alteration, and scanty, apoptotic keratinocytes. Direct immunofluorescence was positive for C3, C4, IgG, fibrin, and superficial dermal globules (apoptotic bodies). The extremities showed nail hypoplasia, especially on the 


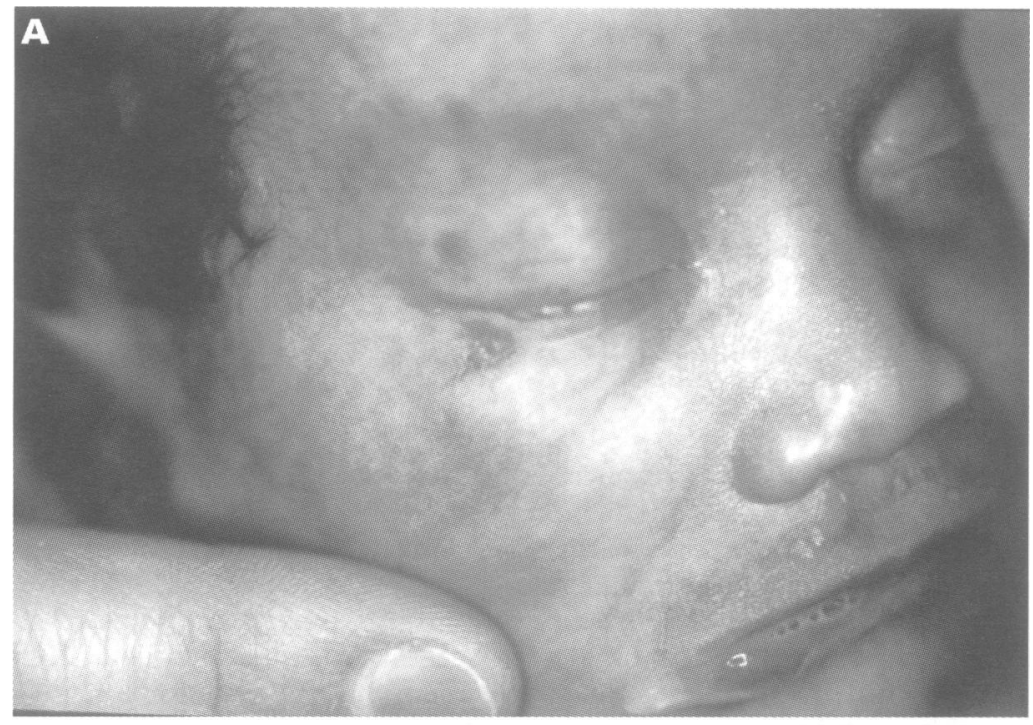

B

Figure $1(A, B)$ Skin lesions, consisting of small annular plaques around the lateral side of the orbit, and facial dysmorphism, consisting of poorly developed brow ridges, depressed nasal bridge, and nasal hypoplasia, in the patient with neonatal lupus.

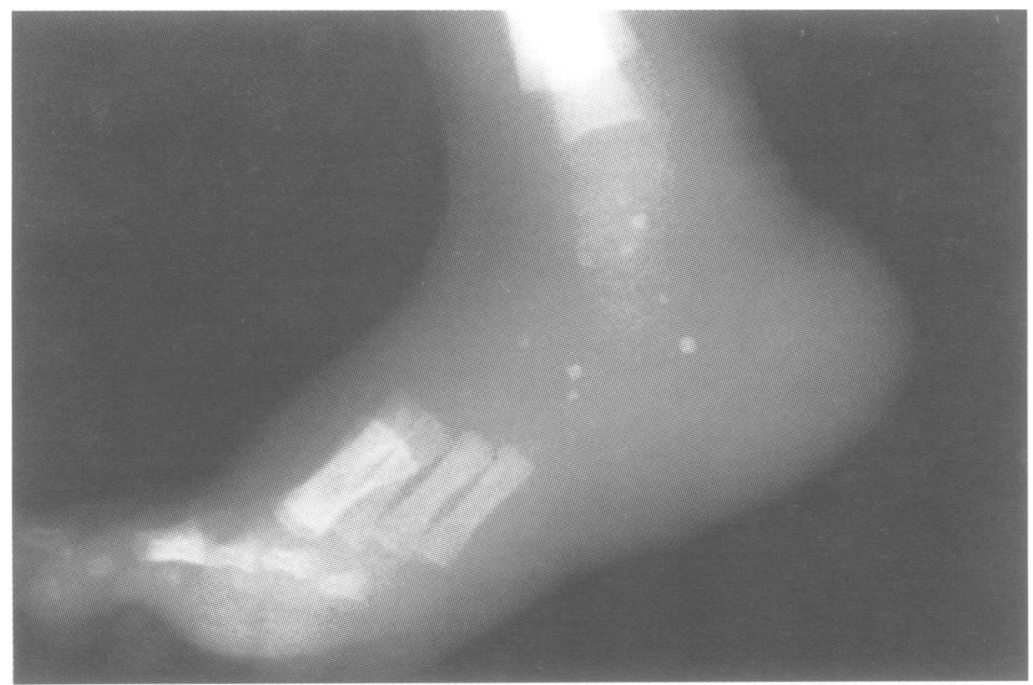

Figure 2 Osteochondrodysplasia punctata (stippled epyphises) in the heel of the patient with neonatal lupus.

hands, and she had prominent heels. A possible diagnosis of cardiopathy was discarded. She was discharged from the clinic at 39 days of age in good condition.
LABORATORY FINDINGS

Haematological alterations consisted of transient thrombocytopenia and leucocyte shift to the left without complications. Diagnosis of infectious disease was discarded. The result of $\mathrm{G}$ banded karyotyping was $46, \mathrm{XX}$. Tests for IgM toxoplasmosis, IgM rubella, and cytomegalovirus in urine were all negative. She had an episode of hypoglycaemia corrected by parenteral treatment.

\section{RADIOLOGICAL FINDINGS}

Osteochondrodysplasia punctata was present in the sacrococcygeal region and in both heels (fig 2), but not in any other part of the skeleton. The rest of the radiological study was normal. Echography of the skull was normal.

\section{Discussion}

We present a patient with neonatal lupus who has a spectrum of clinical manifestations not previously reported to be part of the clinical description of this disease. Chondrodysplasia punctata, one of the anomalous symptoms found in this patient, occurs in numerous inherited conditions and as a consequence of the use of some teratogens, like warfarin or derivatives. $^{5}$

Some of the clinical findings in this patient are similar to congenital anomalies usually related to the use of oral anticoagulants. Because in this case the patient had no previous exposure, an alternative mechanism is suggested which produces the same effect as the anticoagulants. The calcium binding capacity of various proteins can be reduced by interference of vitamin $\mathrm{K}$ dependent post-translational carboxylation of glutamil residues by oral anticoagulants. ${ }^{6}$ During a critical period of ossification in embryonic development, the inhibition of these calcium binding proteins by these drugs could explain the craniofacial anomalies and stippled calcification, as well as other manifestations. ${ }^{4}$

In this case, neonatal lupus could also involve an affected calcium binding protein. In the majority of cases of neonatal lupus, antibodies to Ro/SSA are found, ${ }^{7}$ as in the patient described in this study. Ro/SSA is an autoantigen complex formed by various polypeptides. Some authors have suggested that one of these polypeptides is calreticulin, which is a high affinity calcium binding protein. ${ }^{8}$ However, the participation of calreticulin in this complex is still controversial. ${ }^{910}$ In any case, the pathogenesis of the cutaneous lesions of LE and the congenital heart block associated with neonatal lupus involve antibodies to calreticulin as well as to Ro/SSA..$^{81-12}$

We propose that the findings in this patient, which are similar to the syndrome caused by oral anticoagulants, probably reflect a similar pathophysiology to this syndrome via the interference of a calcium binding protein caused by maternal autoantibodies. There are other possible mechanisms whereby these manifestations could occur, but they are less probable. In vitamin $\mathrm{K}$ epoxide reductase deficiency, there is also an additional congenital, persistent coagulopathy ${ }^{5}$ which is not present here. We can also discard 
malabsorptive vitamin $\mathrm{K}$ deficiency secondary to maternal bowel disorder, which has recently been described as vitamin $\mathrm{K}$ deficiency embryopathy. ${ }^{5}$ None of the drugs prescribed to the mother before or during pregnancy have been reported to have this kind of teratogenic effect.

Antiphospholipid antibodies have also been related to neonatal lupus manifestations. The presence of both anticardiolipin antibodies and lupic anticoagulant at the end of this pregnancy could explain findings such as thrombocytopenia, IUGR, prematurity, and a placenta with multiple infarctions. ${ }^{13-15}$

We suggest that it is advisable for every newborn baby suspected of having neonatal lupus to have a radiological examination of the skeleton to discard the presence of osteochondrodysplasia punctata lesions.

We thank Dr Christine Rousseau for review of the manuscript.

1 De Prost Y, Bodemer C. Neonatal lupus. Ann Med Interne (Paris) 1990;141:250-2.

2 Buyon JP. Neonatal lupus syndromes. Curr Opin Rheumatol 1994;6:523-9.

3 Buyse ML. Fetal warfarin syndrome. Birth defects encyclopedia. New York: The National Institute-March of Dimes, 1990:731-2.
4 Evans M. Coumarin derivatives. Reproductive risk and prenatal diagnosis. London: Appleton Lange 1992:76-7.

5 Menger $\mathrm{H}$. Vitamin $\mathrm{K}$ deficiency embryopathy: a phenocopy of the warfarin embryopathy due to a disorder of embryonic vitamin $\mathrm{K}$ metabolism. Am $\mathcal{f}$ Med Genet 1997;72:129-34.

6 Pauli RM, Lian JB, Mosher DF, Suttie JW. Association of congenital deficiency of multiple vitamin K-dependent coagulation factors and the phenotype of the warfarin embryopathy: clues to the mechanism of teratogenicity of coumarin derivatives. Am f Hum Genet 1987;41:566-83.

7 Lee LA, Frank MB, McCubbin VR, Reichlin M. AutoantiLee LA, Frank MB, McCubbin VR, Reichlin M. Autoanti-
bodies of neonatal lupus erythematosus. $\mathcal{F}$ Invest Dermatol bodies of neonat.

8 Kawashima T, Zappi EG, Lieu TS, Sontheimer RD. Impact of ultraviolet irradiation on expression of SSA/Ro autoantigenic polypeptides in transformed human epiderma keratinocytes. Lupus 1994;3:493-500.

9 Rokeach LA, Haselby JA, Meilof JF, Smeenk RJ, Unnasch TR, Greene BM, Hoch SO. Characterization of the autoantigen calreticulin. F Immunol 1991;147:3031-9.

10 Orth T, Dorner T, Meyer Zum Buschenfelde KH, Maye WJ. Complete congenital heart block is associated with increased autoantibody titers against calreticulin. Eur $\mathcal{F}$ Clin Invest 1996;26:205-15.

11 Nguyen TO, Capra JD, Sontheimer RD. Calreticulin is transcriptionally upregulated by heat shock, calcium and heavy metals. Mol Immunol 1996;33:379-86.

12 Buyon JP. Neonatal lupus: bedside to bench and back. Scand f Rheumatol 1996;25:271-6.

13 Sammaritano LR, Gharavi AE, Lockshin MD. Antiphospolipid antibody syndrome: inmunologic and clinical aspects. Semin Arthritis Rheum 1990;20:81-96.

14 Le Thi Huong D, Wechsler B, Piette JC, Bletry O, Godeau $P$. Pregnancy and its outcome in systemic lupus erythematosus. Qf Med 1994;87:721-9.

15 Pattison NS, Chamley LW, McKay EJ, Liggins GC, Butler WS. Antiphospholipid antibodies in pregnancy: prevalence and clinical associations. Br $\mathcal{F}$ Obstet Gynaecol 1993;100 909-13. 